\title{
Reflexiones jurídicas entorno al posible papel mediador de la Unión Europea en el contencioso de Gibraltar
}

\author{
Legal considerations on the possible European Union's \\ mediating role in the Gibraltar dispute
}

\author{
Pedro Manuel Quesada LóPEZ* \\ Contratado Predoctoral de Investigación FPU del MECD \\ Área de Derecho Procesal, Universidad de Jaén \\ pquesada@ujaen.es
}

\author{
Rabia M'RABET \\ Doctora en Derecho e Investigadora. Área de Derecho Internacional Público \\ Universidad de Jaén \\ rabieta16@hotmail.com
}

RECIBIDO EL 28 DE SEPTIEMBRE DE 2017/ ACEPTADO EL 18 DE OCTUBRE DE 2017

Resumen: En el presente trabajo se partirá de un aná-
lisis del estado de la cuestión sobre el contencioso entre
España y Reino Unido por la soberanía del territorio y las
aguas, así como el estatuto particularizado que ha tenido
la aplicación del Derecho comunitario a raíz del Acta de
Adhesión de Reino Unido a la Unión Europea, para inten-
tar determinar hasta qué punto es aplicable un plan de
mediación que hasta el momento actual se entendía asu-
mible por la Unión. Tras el Brexit y el cambio de posiciona-
miento de la Unión se avecina un replanteamiento de los
términos de todas las posibilidades de llegar a un acuerdo.

Palabras clave: Conflicto de Gibraltar; modelo económico de Gibraltar; resolución internacional de conflictos; Brexit, Derecho de la Unión Europea.
Abstract: This paper will be based on an analysis of the state of play on the issue of the dispute between Spain and the United Kingdom over sovereignty of the territory and waters, as well as the particular status of the application of Community law following the Act of Accession of the United Kingdom to the European Union, in order to try to determine to what extent a mediation plan, which until now was understood to be acceptable to the Union, is applicable. Following the Brexit and the change in the Union's position, a rethinking of the terms of all the possibilities of reaching an agreement is approaching.

Keywords: Gibraltar dispute; Gibraltar economic model; international dispute settlement; Brexit, European Union law.

Sumario: I. ESTADO DE LA CUESTIÓN: EL «LECHO DE PROCUSTO» DEL MODELO ANTERIOR APLICADO GIBRALTAR EN LA UNIÓN EUROPEA. EL FIN DEL RÉGIMEN ESPECIAL.; I.1. Consideraciones relativas al conflicto de soberanía de la colonia británica de Gibraltar.; I.2. Los derechos y las obligaciones de los ciudadanos de Gibraltar como ciudadanos de la Unión Europea.; I.3. La aplicación asimétrica del Derecho comunitario en el territorio de Gibraltar en relación con su modelo económico y fiscal; II. ESTIMACIONES SOBRE LA APLICACIÓN DE UN PLAN DE MEDIACIÓN DIRIGIDO POR LA UNIÓN EUROPEA.; II.1. Análisis desde una perspectiva histórica.; II.2. ¿Posible solución negociada?; II.3. El papel de la Unión Europa en el conflicto de Gibraltar. Situación post-Brexit.; III. CONCLUSIONES.

* Referencia: FPU014/04912. Artículo realizado en el seno del Proyecto de Investigación: I+D+i del Plan Nacional: Las entidades locales, sus relaciones y competencias. Realidad, efectos y consecuencias de la racionalización y sostenibilidad financiera en clave nacional y europea (DER2016-74843-C3-1-R), del que forma parte de su grupo de trabajo.

** Investigadora del Grupo SEJ-399 «Derecho Común Europeo y Estudios Internacionales». 
I. ESTADO DE LA CUESTIÓN: EL «LECHO DE PROCUSTO» DEL MODELO ANTERIOR APLICADO GIBRALTAR EN LA UNIÓN EUROPEA. EL FIN DEL RÉGIMEN ESPECIAL

\section{I.1. Consideraciones relativas al conflicto de soberanía de la colonia británica de Gibraltar}

$\square$ esde un punto de vista estructural, es preciso determinar las dimensiones y consideraciones relativas al conflicto de soberanía territorial y marítima sobre Gibraltar, con el objetivo de obtener una perspectiva global del contencioso y facilitar el establecimiento de presupuestos objetivos que faciliten la consecución de un programa y pautas de mediación internacional. Como es sabido, el texto de referencia en relación a la soberanía del territorio es el artículo X del Tratado de Utrecht de 13 de julio de 1713, en el que se estableció la cesión de territorio en su párrafo primero ${ }^{1}$. Destaca también la adopción de una estipulación de derecho de retracto (o «pre-emption right») a favor de España en el último párrafo, según el cual si Gran Bretaña decide la ciudad de Gibraltar, se dará a la Corona de España la primera acción antes que a otros, condicionándose la soberanía de Reino Unido a la hora de desprenderse del territorio ${ }^{2}$.

Es preciso, por tanto diferenciar, a efectos del estudio de las zonas en disputa: el territorio cedido strictu sensu por vía del Tratado de Utrecht, la zona del Monte Calpe y el istmo. Respecto de cada uno de los enunciados las partes en controversia alegan distintos títulos de adquisición, adquiriendo el contencioso disímiles escenarios. En relación a los territorios cedidos por el tratado de Utrecht, podría interpretarse la existencia de un acuerdo tácito entre las partes en relación a la legitimidad del Tratado de Utrecht ${ }^{3}$. Cabe también

1 «El Rey Católico, por sí y por sus herederos y sucesores, cede por este Tratado a la Corona de la Gran Bretaña la plena y entera propiedad de la ciudad y castillo de Gibraltar, juntamente con su puerto, defensas y fortaleza que le pertenecen, dando la dicha propiedad absolutamente para que la tenga y goce con entero derecho y para siempre, sin excepción ni impedimento alguno». Versión de la publicación del Ministerio de Asuntos Exteriores y Cooperación La cuestión de Gibraltar, publicado en Madrid, 2009, p. 85.

2 Para un interesante estudio de la controversia hispano-británica a propósito de Gibraltar vid. FERnÁNDEZ SÁNCHEZ, P.A., «La controversia sobre la titularidad jurídico-internacional de los espacios marítimos adyacentes a Gibraltar», Revista Española de Derecho Internacional, vol. 67, 2, 2015, pp. 13-47.

3 Del Valle Gálvez, A. «¿De verdad cedimos el peñón? Opciones estratégicas de España sobre Gibraltar a los 300 años del Tratado de Utrecht», Revista Española de Derecho Internacional, vol. LXV, 2013, p. 122. 
indicar la existencia de un sector de la doctrina española que asegura que la cesión del territorio se ha llevado a cabo por una modalidad de soberanía territorial denominada cesión forzosa, precedido por la conquista británica que impone por las armas las condiciones del Tratado ${ }^{4}$. Este punto es contrastado por la propia doctrina española, que trae a colación la idea de que la cesión se confirmó por los Tratados posteriores de Sevilla del año 1729, Aquisgrán de 1748, París de 1763 y Versalles de $1783^{5}$.

El territorio cedido por el tratado se limita a la ciudad, castillo, puerto, defensas y fortaleza. De este modo la delimitación del territorio que se cede por el tratado se restringe sólo a ello. Por tanto la doctrina plantea dudas respecto al alcance de la cesión del Monte Calpe hasta Punta Europa, que ha originado dudas interpretativas por parte de las autoridades españolas ${ }^{6}$. Se pon de manifiesto también que en el Tratado de Utrecht en la cesión de Menorca (art. XI) se diferencia entre la cesión de la ciudad y el castillo respecto del resto de territorio cedido (como es la isla de Menorca). En todo caso se apunta, desde la doctrina española que la prescripción adquisitiva podría ser un título adquisitivo alegado por Reino Unido para justificar la soberanía sobre el Peñón 7.

Otro argumento usado por la doctrina es el uso de la expresión «propiedad» en lugar de «soberanía» en el tenor literal del Tratado, unida al hecho de que en el párrafo segundo del art. $\mathrm{X}$ se indica que la propiedad se cede «sin jurisdicción territorial alguna». De este modo bajo esta interpretación España cedería el territorio de Gibraltar en el sentido jurídico-civil de la palabra (potestas) sin cesión de soberanía jurídico-internacional del estado español $(\text { autorictas })^{8}$. No obstante otra opinión acepta la aplicación de la jurisprudencia

4 IZquierdo SANS, C., Gibraltar en la Unión Europea. Consecuencias sobre el contencioso hispánicobritánico y el proceso de construcción europea, Tecnos (Universidad Autónoma de Madrid), Madrid, 1996, p.25.

5 VERDÚ BAEZA, J. «La controversia sobre las aguas de Gibraltar: el mito de la costa seca», Revista Española de Derecho Internacional, vol. LXVI, 2014, p. 85.

6 En la contestación del General Gobernador Militar del Campo de Gibraltar a la protesta del Gobernador de Gibraltar por la construcción de una puerta en la verja inglesa que separa Gibraltar del resto de España, dada en Algeciras a 30 de noviembre de 1954, el Gobernador expone que según el Tratado de Utrecht, la frontera inglesa es el límite Norte de la Roca. Versión de la publicación del Ministerio de Asuntos Exteriores y Cooperación La cuestión de Gibraltar, publicado en Madrid, 2009, p. 88.

7 Del VAlle GálVEZ, «¿De verdad...», op. cit., pp. 124-125.

8 Defendido por AzcárRaga Bustamante, J., en su obra «Las aguas españolas de Gibraltar», Estudios de Derecho Internacional Público y privado. Homenaje al profesor Luis Sela Stampil, publicado por la Universidad de Oviedo, 1970, p. 70; y citado por VERDÚ BAEZA, «La controversia...», op. cit., p. 89. 
del Tribunal Internacional de Justicia ${ }^{9}$, en concreto la Sentencia de 12 de abril de 1960 (Right of Passage over Indian Territory Case) ${ }^{10}$ según la cual las cesiones de territorio se han de interpretar necesariamente como cesiones de soberanía.

Cuestión distinta constituye la controversia territorial sobre el istmo, territorio que en ningún momento se cede en el Tratado de Utrecht. Según la doctrina ${ }^{11}$, la posición británica sólo tendría modo de adquirir un título justificativo de adquisición mediante la prescripción adquisitiva, aspecto muy discutido y contrapuesto por la posición española (a diferencia del Monte Calpe). Bajo una visión cronológica, entre 1908 y 1909, como fruto de la expansión territorial británica más allá de los límites tradicionales delimitados en el Tratado se construyó la verja por la parte británica, siendo ésta usada de facto como una delimitación fronteriza por parte de Reino Unido, pero que como fue declarado expresamente por Reino Unido en 1909 tal verja no constituía en ningún modo una frontera ${ }^{12}$. Posteriormente en 1966 la posición británica sobre la Verja cambió, argumentando que sí que era una frontera ${ }^{13}$ y que el territorio se había adquirido bajo la modalidad de prescripción adquisitiva ${ }^{14}$.

Un aspecto valorado ha sido la existencia de los elementos de la prescripción adquisitiva de Derecho internacional. Esta vía de adquisición de la competencia territorial se fundamenta en la adquisición de soberanía sobre un territorio del que un tercer Estado ha gozado con anterioridad de soberanía. Como elementos, se señala que el estado ha de ejercer soberanía efectiva de funciones estatales durante un periodo de tiempo, cuyo lapso será suficiente cuando de lugar a un reconocimiento general del título. Este ejercicio debe efectuarse de forma continuada e ininterrumpida además de pacífica y públi-

9 VERDÚ BAEZA, «La controversia...», op. cit., p. 90.

10 Tribunal Internacional de Justicia. Case concerning right of passage over indian territory. Disponible on line en http://www.icj-cij.org/docket/files/32/4521.pdf [3 de junio de 2017].

11 IZQUIERDO SANS, Gibraltar en la Unión..., op. cit., p. 35.

12 Del VAlle GálVEZ, «¿De verdad...», op. cit., p. 127.

13 Así, en la Declaración del Presidente de la delegación británica (Sr. Hohler) de 12 de julio de 1966 se indicó en su punto II que «el territorio entre la verja fronteriza de Gibraltar y el pie de la Roca es también territorio bajo soberanía británica. Cualquier acción que violase dicha soberanía sería de la mayor seriedad». Vid. publicación del Ministerio de Asuntos Exteriores y Cooperación La cuestión de Gibraltar..., op. cit., p. 92.

14 En las notas verbales de 21 de julio y 6 de agosto de 1966 la posición británica argumentó que «cualesquiera que sean las limitaciones territoriales de la cesión de Gibraltar dispuestas por España en el Tratado de Utrecht, el Gobierno de su Majestad, confía en que en cualquier caso ba adquirido un título prescriptivo sobre Gibraltar entre el pie norte de la Roca y la actual verja fronteriza». Citado por IZQUIERDO SANS, Gibraltar en la Unión..., op. cit., p. 36. 
ca. Esto implica la total ausencia de protesta por el Estado que ostentase la soberanía anterior. Esta aquiescencia se basaría en el conjunto de la falta de protesta y el silencio por parte del estado frente al que se opone la prescripción adquisitiva ${ }^{15}$.

Surgiría así una discrepancia entre Reino Unido y España por la soberanía del istmo. La posesión británica del istmo en ningún momento ha sido pacífica por parte de España, que desde el siglo XIX ha procedido periódicamente a emitir notas de protesta por la ocupación el istmo ${ }^{16}$; y ya entrado el siglo XX en el 6 de abril de 1909 una vez que se erigió la verja y ordenando la realización de otra nota de protesta al embajador en Londres el 4 de mayo de 1939 por la construcción del aeródromo, trasladándose posteriormente en la década de 1960 el escenario de protestas a la negociación en el seno de Naciones Unidas tendente a la descolonización. Como consecuencia de esta problemática es preciso señalar el cierre de la frontera terrestre entre el 8 de junio de $1969^{17}$ y su reapertura el 14 de diciembre de $1982^{18}$.

Cabría entonces plantearse la aplicación de dos precedentes: en primer lugar la del asunto Haya de la Torre ${ }^{19}$ en virtud de la cual la aceptación de hechos por cortesía u oportunidad política no equivaldrían en ningún modo a un reconocimiento ${ }^{20}$; y el asunto de las Islas Minquiers y Ecrehos ${ }^{21}$ mediante la cual no se puede considerar como prueba suficiente de la intencionalidad

15 IZQUIERdo SANS, Gibraltar en la Unión..., op. cit., pp.37-41.

16 En fechas de 21 de abril de 1845, de 13 de noviembre de 1863, de 8 de julio de 1881 y mayo de 1882. Ministerio de Asuntos Exteriores, Documentos sobre Gibraltar. Citado por IzQUIERDO SANS, Gibraltar en la Unión..., op. cit., p. 41.

17 El problema se acució cuando el 12 de julio de 1996 en la declaración del Presidente de la Delegación británica (Sr. Hohler) se explicitó que «el territorio entre la verja fronteriza de Gibraltar y el pie de la Roca es también territorio bajo soberanía británica». A consecuencia de ello el Ministerio Español de Asuntos exteriores informó al a Embajada británica el 21 de julio de 1996 que «la soberanía española se extiende al territorio comprendido entre la verja cosntruída por las autoridades inglesas y las muralllas de Gibraltar».

18 Con la llegada de la democracia y el Gobierno socialista a España, se reestableció el tráfico peatonal por Acuerdo del Consejo de Ministros de 7 de diciembre de 1982. Publicado en BOE $\mathrm{n}^{\circ}$ 297, de 11 de diciembre de 1982, pp. 34018 a 34018.

19 Sentencia de 13 de junio de 1951 del Tribunal Internacional de Justicia. Haya de la Torre (Colombia v. Perú). Disponible on line en http://www.icj-cij.org/docket/files/14/1937.pdf [3de junio de $2017]$.

20 Antón Guardiola, C., Gibraltar: un desafío en la Unión Europea, Tirant lo Blanch, Valencia, 2011, pp. 72-73.

21 Sentencia de 17 de noviembre de 1953 del Tribunal Internacional de Justicia. Minquiers and Ecrehos case. Disponible on line en http://www.icj-cij.org/docket/files/14/1937.pdf [3de junio de 2017] 
de un gobierno para la obtención de un título de soberanía ni manifestación de autoridad estatal la asunción de servicios eléctricos, efectuación de visitas oficiales o la edificación de construcciones por parte del estado reclamante (en alusión a la construcción del aeródromo, sobre el que se realizó la oportuna protesta por escrito el 1 de mayo de 1940).

Por lo tanto el debate sobre la legitimidad del título de prescripción adquisitiva británica sobre el istmo es, cuanto menos, controvertida entre las partes del contencioso ${ }^{22}$.

No menos interés despierta el proceso de descolonización iniciado en Naciones Unidas. El 16 de octubre de 1964 el Comité Especial de Descolonización adoptó un consenso por el que se invitaba a Reino Unido y a España a iniciar conversaciones a fin de encontrar una solución negociada conforme a las disposiciones de la resolución 1514 (XV) de la Asamblea General ${ }^{23}$. Este documento abrió de este modo un esquema de trabajo en Naciones Unidas cuyo contenido se plasmó en la Resolución 2070 (XX) de 16 de diciembre de 1965 de la Asamblea General, primero en el que se invita a las partes a iniciar una negociación. Posteriormente la Resolución 2231 (XXI) de 20 de diciembre de 1966 de la Asamblea General pidió la continuación del proceso de descolonización teniendo en cuenta el interés de la población y requirió a los gobiernos británico y español que no obstaculizasen el proceso de negociación respecto del Gobierno de España. No obstante el incumplimiento se volvió a poner de manifiesto en la Resolución 2353 (XXII) de 8 de enero de 1968 en la que se declara la contravención por parte de Gobierno de Reino Unido por la celebración de un referéndum en Gibraltar por ser contrario a los propósitos de la Resolución 2231, en la que se parte de la idea de que la situación colonial que destruye la integridad territorial de un país es incompatible con los prin-

22 Sin perjuicio de propuestas unilaterales de solución amistosa del contencioso. Se destaca así las propuestas del Ministro español de Asuntos Exteriores Fernando Morán, que en su comparecencia ante la Comisión de Asuntos Exteriores del Congreso de los Diputados para informar de las negociaciones con Reino Unido el 7 de marzo de 1985 propuso entre otras soluciones al istmo un condominio a través de un órgano común de gestión, o un arriendo a Reino Unido que fuese precedido de una cesión total a España por un Convenio que novase le artículo $\mathrm{X}$ del Tratado de Utrecht. Citado por Remiro Brotons, A., «Regreso a Gibraltar: acuerdos y desacuerdos hispano-británicos», Universidad Autónoma de Madrid, Revista furídica, 2004, p. 155. Tal postura ha vuelvo a ser manifestada por el Ministro español Alfonso Dastis, si bien no condicionada a la negociación entre España y Reino Unido por la salida de esta última de la Unión Europea: http://www.abc.es/espana/abci-no-condiciono-acuerdo-londres-ue-recuperargibraltar-201708060327_noticia.html [Consulta: 8 de agosto de 2017]

23 REMIRo BRotons, «Regreso a Gibraltar...», ibid., pp. 139-141. 
cipios recogidos en la Carta, y se vuelve a invitar a reanudar las negociaciones pidiendo además al Secretario General que preste ayuda a los gobiernos de España y Reino Unido. Similares contenidos se plasmaron en la Resolución 2429 (XXII) de 1 de diciembre de 1968 de la Asamblea General donde se pide a Reino Unido como Potencia administradora el término de la situación colonial antes de una fecha concreta (1 de octubre de 1969). Desde entonces la postura de Naciones Unidas ha tendido en tal sentido: la Resolución 3163 (XXVIII) de 14 de diciembre de 1973 de la Asamblea General advierte de los efectos potencialmente perjudiciales del conflicto y vuelve a instar a la búsqueda de un acuerdo y la negociación, y en la Resolución 3286 (XXIX) de 13 de diciembre de 1974 vuelve a urgir a los gobiernos parte del contencioso a reanudar las negociaciones e informar del resultado de las mismas ${ }^{24}$.

Respecto a la soberanía marítima sobre las aguas adyacentes a la zona de Gibraltar constituye también otra arista importante del contencioso. Desde el punto de vista histórico ${ }^{25}$, a lo largo de los siglos XVIII, XIX y hasta la mitad del XX España no ha negado el derecho de Gibraltar a extender su soberanía sobre las aguas adyacentes a Gibraltar. Existe un documento jurídico que reconoce los límites de las aguas de la Bahía de Algeciras con límite en las de Gibraltar a efectos de persecución del contrabando (Real Decreto de 10 de diciembre de 1876). Señala el autor citado que durante el siglo XIX no se cuestionaba la existencia de aguas bajo la soberanía de Reino Unido, sino la delimitación; y no sería hasta la llegada de la dictadura franquista, según el autor, cuando la posición española defendió la teoría de la costa seca ${ }^{26}$.

La posición de costa seca puede enunciarse a la luz de diferentes textos jurídicos españoles. Así, en la protección del espacio aéreo la Orden de 18 de enero de 1993 sobre zonas prohibidas y restringidas al vuelo (que sucede a la Orden de 15 de marzo de 1985$)^{27}$ establece respecto la zona de la Bahía de Algeciras y Gibraltar que no significan una delimitación del territorio nacional, ni la renuncia a los derechos soberanos de España al sur de los mismos. Así la Ley 10/1977, de 4 de enero, sobre mar territorial2 ${ }^{28}$ en su Disposición

24 Organización de Naciones Unidas. Resoluciones de la Asamblea General de Naciones Unidas [en línea]. Dirección URL: http://www.un.org/es/documents/ag/resga.shtml [consulta: 5 junio 2017]

25 VERDÚ BAEZA, «La controversia...», op. cit., p. 100.

26 Ibid., pp. 98-99.

27 Publicado en BOE no 20, de 23 de enero de 1993, pp. 1872 a 1877.

28 Publicado en el BOE n ${ }^{\circ}$, de 8 de enero de 1977, pp. 373 a 374. 
Final Primera, y el punto segundo del Instrumento de ratificación del Reino de España de la Convención de las Naciones Unidas sobre el Derecho del Mar, hecho en Montego Bay el 10 de diciembre de $1982^{29}$ donde se efectúa un límite de interpretación del Convenio respecto del reconocimiento de los derechos o situaciones relativas a los espacios marítimos de Gibraltar que no estén comprendidos en el artículo 10 del Tratado de Utrecht.

Respecto de esta Declaración la doctrina guarda dudas en referencia a la efectividad de la misma, debido a la prohibición de formulación de reservas contenido en el propio texto de la Convención de Naciones Unidas sobre derecho del mar. Así el artículo 309 de la Convención de las Naciones Unidas sobre el Derecho del Mar establece que no podrán formular reservas ni excepciones a la Convención. Además el artículo 310 de la misma establece la posibilidad de los Estados de efectuar declaraciones al firmar o ratificar la Convención o adherirse a ella, cualquiera que sea su enunciado o denominación, a fin de (entre otras cuestiones) armonizar el derecho interno con las disposiciones de la Convención; estableciéndose como condicionante que tales declaraciones o manifestaciones no tengan por objeto excluir o modificar los efectos jurídicos de las disposiciones de la Convención en su aplicación al Estado. De esta forma la doctrina pone en tela de juicio el valor jurídico de las declaraciones unilaterales de España, teniendo en cuenta el marco general del Convenio ${ }^{30}$.

Por igual son varios los principios jurídicos que podrían ser invocados al efecto: (i) el criterio «la tierra domina al mar» perfilado por primera vez por el Tribunal Internacional de Justicia en el caso de Delimitación de la Frontera Marítima en la Región del Golfo de Maine ${ }^{31}$; (ii) el carácter internacional que tiene la delimitación de las zonas marítimas y que no puede depender únicamente de

29 Publicado en el BOE $\mathrm{n}^{\circ}$ 39, de 14 de febrero de 1997, pp. 4966 a 5055. El texto tiene el tenor literal siguiente: «España, en el momento de proceder a la ratificación, declara que este acto no puede ser interpretado como reconocimiento de cualesquiera derechos o situaciones relativas a los espacios marítimos de Gibraltar que no estén comprendidos en el artículo 10 del Tratado de Utrecht, de 13 de julio de 1713, suscrito entre las Coronas de España y Gran Bretaña. España considera, asimismo, que la Resolución Ill de la Tercera Conferencia de las Naciones Unidas sobre el Derecho del Mar no es aplicable al caso de la Colonia de Gibraltar, la cual está sometida a un proceso de descolonización en el que son aplicables exclusivamente las resoluciones pertinentes adoptadas por la Asamblea General de la Organización de las Naciones Unidas».

30 VERDÚ BAEZA, «La controversia...», op. cit., p. 108.

31 Sentencia de 12 de octubre de 1984 del Tribunal Internacional de Justicia. Delimitation of the Maritime Boundary in the Gulf of Maine Area (Canada/United States of America). Disponible on line en http://www.icj-cij.org/docket/files/67/6369.pdf [3de junio de 2017]. 
la voluntad del Estado ribereño como establezca en su derecho interno (puesto que si el acto de delimitación es unilateral, su validez respecto a otros Estados dependerá del derecho internacional) como se clarifica en el Caso Pesquerías ${ }^{32}$ y (iii) y el principio clásico de «lex posterior derogat legi priori» (la ley anterior deroga la posterior), entendiendo que si tanto España como Reino Unido son Estados parte del Convenio de Naciones Unidas de Derecho del Mar hecho en Montego Bay el 10 de diciembre de 1982 éste derogará o modificará las disposiciones (en materia de Derecho marítimo) del Tratado de Utrecht así como el resto de normas jurídicas bilaterales, multilaterales o unilaterales. El Convenio es claro en este sentido: el artículo 3 dispone que todo Estado tiene derecho a establecer la anchura de su mar territorial hasta un límite que no exceda de 12 millas marinas, y puesto que la costa de la Bahía de Algeciras es adyacente y se encuentra frente a frente con Gibraltar según el artículo 15 del Convenio el mar territorial se extenderá mediante una línea media cuyos puntos sean equidistantes de los puntos más próximos de las líneas de base a partir de las cuales se mida la anchura del mar territorial tanto de España como de Reino Unido ${ }^{33}$. De esta forma la tesis de la «costa seca» en ningún modo tendría virtualidad bajo el Derecho internacional reconociendo el derecho de Reino Unido al mar territorial en Gibraltar. Esto no es óbice para delimitar el fragmento de mar territorial en disputa. Si bien no cabe duda que la legitimidad de Gibraltar para ostentar soberanía de mar territorial a la luz del Derecho internacional, ello no le permite extenderla sobre un territorio claramente en disputa ${ }^{34}$.

\section{I.2. Los derechos y las obligaciones de los ciudadanos de Gibraltar como ciudadanos de la Unión Europea}

Como punto de partida, es preciso delimitar las especificidades que ha despertado, tanto en la doctrina como en la jurisprudencia, la aplicación asimétrica de los derechos y las obligaciones de los ciudadanos de Gibraltar en cuanto a ciudadanos de la Unión Europea y en concreto de sus derechos po-

32 Sentencia del Tribunal Internacional de Justicia de 18 de diciembre de 1951. Fisheries (United Kingdom v. Norway). Disponible on line en http://www.icj-cij.org/docket/files/5/1809.pdf [3de junio de 2017].

33 NALDI, G., «The Status of the Disputed Waters Surrounding Gibraltar», The International fournal of Marine and Coastal Law, 28, 2013, p. 717.

34 VERDÚ BAEZA, «La controversia...», op. cit., p. 111. 
líticos de participación en las elecciones en el ejercicio de sus derechos de sufragio activo y pasivo.

Ha sido constante la evolución entre los primeros conatos de una delimitación de derechos fundamentales en el marco de la jurisprudencia del Tribunal de Justicia de las Comunidades Europeas ${ }^{35}$ y la proclamación de la Carta de los Derechos Fundamentales de la Unión Europea de Niza de 2000 refrendada por el Tratado de Lisboa en su artículo $6^{36}$, pasando por la adhesión de la Unión Europea a la Convención Europea de Derechos Humanos y la propia Carta de Niza de 2000. Cabe por igual destacar y señalar en este punto el caso particular que supuso Reino Unido, junto a Polonia ${ }^{37}$, los cuales formularon reservas sobre de la Carta de Niza durante las negociaciones del Tratado de Lisboa en el año 2007. De hecho el Tratado de Lisboa modifica el artículo 6 del Tratado de la Unión Europea para establecer que la Unión reconoce los derechos, libertades y principios enunciados en la Carta de los Derechos Fundamentales de Niza, dotándola con el mismo valor jurídico que los Tratados.

No obstante en el Protocolo $n^{\circ} 30$ sobre la aplicación de la Carta de los Derechos Fundamentales de la Unión Europea a Polonia y al Reino Unido ${ }^{38}$, no amplía en su artículo 1 la competencia del TJUE ni de ningún otro órgano jurisdiccional de Polonia o del Reino Unido ${ }^{39}$. Llegados a este punto, cabe volver a destacar las particularidades en la aplicación del Derecho europeo en el territorio de Gibraltar. Tales vicisitudes fueron puestas de relieve en la Sentencia del Tribunal Europeo de Derechos Humanos de 19 de febrero de 1999 (Caso Matthews v. United Kingdom) ${ }^{40}$. Con anterioridad al comentado caso,

35 Sentencia del Tribunal de Justicia de las Comunidades Europeas de 12 de noviembre de 1969 (Caso Stauder), en cuyo Fundamento Jurídico $7^{\circ}$ ya apuntaba un reconocimiento expreso de los derechos fundamentales de la persona susceptibles de su protección a manos del Tribunal: «interpretada de este modo, la disposición controvertida no ba revelado ningún elemento que permita cuestionar los derechos fundamentales de la persona subyacentes en los principios generales del Derecho comunitario, cuyo respeto garantiza el Tribunal de fusticia».

36 Diario Oficial de las Comunidades Europeas. Fecha de 18.12.2000, C 364/1

37 García RoCa, J. y FernáNDEZ SÁNCHEZ, A., Integración europea a través de derechos fundamentales: de un sistema binario a otro integrado, Centro de Estudios Políticos y Constitucionales, Madrid, 2009, p. 11.

38 Diario Oficial de la Unión Europea. Fecha de 17.12.2007, C 306/157.

39 Según el tenor literal del precepto, «para apreciar que las disposiciones legales o reglamentarias o las disposiciones, prácticas o acciones administrativas de Polonia o del Reino Unido sean incompatibles con los derechos, libertades y principios fundamentales».

40 Tribunal Europeo de Derechos Humanos. Matthews v. Reino Unido (Application no. 24833/94). Disponible on line en http://hudoc.echr.coe.int/sites/eng/pages/search.aspx?i=001-58910\#\{《itemid»: [«001-58910»]\} [3de junio de 2017]. 
los ciudadanos de Gibraltar eran excluidos de las elecciones al parlamento europeo. A raíz del mismo se reconoció la obligación de Reino Unido de permitir el derecho de sufragio de los ciudadanos de Gibraltar en las elecciones del parlamento europeo; interpretando que para que el precepto del artículo 56- $3^{\circ}$ del Convenio Europeo de Derechos humanos fuese aplicado era necesaria la prueba manifiesta y clara de una necesidad local (fj 59); requisito que el Tribunal no encontró justificado en el estatuto de Gibraltar, indicando de contrario que podría constituir una limitación al CEDH. También se constató la infracción del artículo 3 del Protocolo ${ }^{\circ} 1$ del CEDH, que obliga a las Partes Contratantes a organizar, en intervalos razonables, elecciones libres con escrutinio secreto en la elección del cuerpo legislativo.

La doctrina del «Caso Matthews» fue consolidada, de igual forma, en la Sentencia del Tribunal de Justicia de las Comunidades Europeas de 12 de septiembre de 2006 (Asunto c-145/04), en un recurso de incumplimiento planteado por España al considerar que los gibraltareños no tenían la condición de nacionales comunitarios. El Tribunal consideró que la determinación de los titulares del derecho de sufragio activo y pasivo en las elecciones al Parlamento Europeo es competencia de cada Estado miembro, no oponiéndose el Derecho primario (FJ. 78).

Aunque la cuestión del derecho de sufragio activo y pasivo ya ha sido superada, es importante poner de relieve el carácter peculiar del estatuto jurídico de Gibraltar en cuanto a la exclusión parcial del territorio a efectos aduaneros y fiscales en relación a sus habitantes, que poseen la condición de ciudadanos de la Unión Europea.

\section{I.3. La aplicación asimétrica del Derecho comunitario ${ }^{41}$ en el territorio de Gibraltar en relación con su modelo económico y fiscal}

Dentro del estudio particularizado de las distintas dimensiones del contencioso entre Reino Unido y España he decidido profundizar y aplicar específicamente los procedimientos de mediación a la problemática de la integración del territorio y su modelo económico en la Unión Europea.

41 En el presente trabajo los autores empleamos la denominación «Derecho comunitario», conscientes de que, tras la entrada en vigor del Tratado de Lisboa, es más correcto el empleo en su lugar de «Derecho de la Unión Europea». 
Sin duda, antes del referéndum sobre la permanencia del Reino Unido en la Unión Europea, existía una clara aplicación diferenciada del Derecho de la Unión Europea en el territorio de Gibraltar. Ha de partirse de un precepto general que es el recogido en el artículo 355.3 del Tratado de Funcionamiento de la Unión Europea ${ }^{42}$ (TFUE), el cual estipula que las disposiciones de los Tratados se aplicarán a los territorios europeos cuyas relaciones exteriores asuma un Estado miembro, del que era Reino Unido en relación a Gibraltar.

El complejo estatuto jurídico de dicho territorio unido dado de su condición como territorio británico de ultramar, en adición a las diferentes reservas formuladas en los Tratados por parte de Reino Unido dan lugar a distintas particularidades tanto económicas como financieras que provocan que si bien Gibraltar se encontraba integrado en un estado parte de la Unión Europea a su territorio no les eran aplicables parte de las importantes las regulaciones emanadas de la Unión Europea.

A efectos del presente trabajo y siguiendo el criterio doctrinal puede clasificarse la aplicación asimétrica del derecho comunitario en varias facetas: (i) en la exclusión del espacio de libre circulación de mercancías; (ii) en la dispersa o nula aplicación de la regulación de armonización de imposición indirecta; y (iii) en la configuración del sistema impositivo directo ${ }^{43}$.

En el Acta de 1972 relativa a las condiciones de adhesión ya las adaptaciones de los Tratados de las Comunidades Europeas por parte de Reino Unido ${ }^{44}$ se establecía tal exclusión para Gibraltar en su artículo 28. De la interpretación de este precepto deduce la doctrina que si bien el territorio de Gibraltar se encuentra integrado en la Unión Europea, en la aplicación de las políticas económicas descritas se le aplica un régimen análogo al de un tercer estado ${ }^{45}$.

La exclusión del espacio del Espacio Aduanero Comunitario viene dada también por la Reforma del Reglamento 1496/68 de 27 de septiembre de 1968, relativo a la delimitación del Espacio Aduanero Comunitario, y que con

42 Publicado en el Diario Oficial de la Unión Europea n 83, de 30 de marzo de 2010, pp. 47 a 199

43 AnTón Guardiola, Gibraltar: un desafío..., op. cit., pp. 134-183.

44 «Los actos de las instituciones de la Comunidad en relación con los productos del Anexo II del Tratado CEE y a los productos sometidos, a su importación en la Comunidad a una regulación específica como consecuencia de la aplicación de la política agrícola común, así como los actos en la armonización de las legislaciones de los Estados miembros en materia de impuestos sobre el volumen, no se aplicará a Gibraltar, a menos que el Consejo, por unanimidad, a propuesta de la Comisión, disponga otra cosa» Official Journal of the European Communities. Ref. 27. 3. 72. Disponible on line en http://eur-lex.europa.eu/LexUriServ/LexUriServ.do?uri=OJ:L:1972:073:FULL:EN:PDF [28 de mayo de 2017].

45 AnTón Guardiola, Gibraltar: un desafío..., op. cit., p. 137. 
la firma del Acta de Adhesión de Reino Unido y la introducción de su Anexo I se modifica el ámbito de aplicación indicando que el territorio aduanero comunitario comprenderá el territorio de Reino Unido e Irlanda del Norte, las Islas del Canal y la Isla de Man, no incluyendo por tanto el territorio de Gibraltar dentro de susodicho espacio.

La exclusión del Espacio Aduanero Comunitario ha sido el presupuesto de los controles fronterizos efectuados por España ${ }^{46}$. La propia Comisión Europea, en la contestación a varias preguntas escritas en materia de los controles realizados por España, ha determinado que si bien Gibraltar forma parte de los territorios a los que se les aplican las normas de derecho primario, no obstante está excluido del territorio aduanero, por lo cual no les sería de aplicación las normas relativas a la libre circulación de mercancías en los intercambios entre Gibraltar y España, ya que las mercancías procedentes de nuestro país quedarían integradas en el régimen común de importación de la Unión Europea.

Por medio del TFUE se establecen las bases fundamentales de la libre circulación de mercancías (arts. 28-29) y la unión aduanera (arts. 30-32), así como el principio de cooperación aduanera del artículo 33 que obliga a las instituciones legislativas de la Unión a adoptan medidas destinadas a fortalecer la cooperación aduanera entre los Estados miembros. El artículo 28.1 del Tratado de Funcionamiento detalla que la unión aduanera abarcará la totalidad de los intercambios de mercancías y la prohibición, entre los Estados miembros, de los derechos de aduana de importación y exportación u equivalentes, así como la adopción de un arancel aduanero común en sus relaciones con terceros países. La propia jurisprudencia del Tribunal de Justicia de las Comunidades Europeas vincula como condición previa indispensable para la realización de una unión aduanera la consagración del principio de libre circulación de mercancías (Sentencia de 9 de agosto de 1994, en los asuntos acumulados C-363/93, C-407/93, C-408-93, C-409/93, C-410/93 y C-411/93, punto 29).

No encontrándose integrado el territorio de Gibraltar en la unión aduanera, se consideraría que las mercancías entrantes de Gibraltar tendrían el mismo régimen jurídico que los productos que accediesen desde un tercer estado, por lo que se aplicarían los derechos de aduana comunitarios (Arancel Aduanero Común), y que por el contrario las mercancías que se exportasen al

46 Citado por ANTÓN Guardiola, Gibraltar: un desafío..., op. cit., pp. 141-142. El contenido se encuentra en el JOCE $\mathrm{n}^{\circ} \mathrm{C}-341$ de 31 de diciembre de 1985, en contestación a las preguntas $1823 / 84,1824 / 84$ y $1825 / 84$. 
territorio británico de ultramar serían gravadas por los derechos aduaneros propios de Gibraltar ${ }^{47}$ (Gibraltar Customs Integrated Tariff), recogidos en la Import and Export Regulation de 1987 y la Import duty (integrated tariff) regulations, de $1993^{48}$.

A esta conclusión llega el Tribunal de Justicia de las Comunidades Europeas en el punto 39 de la sentencia de 23 de septiembre de 2003 (asunto C-30/2001, Comisión contra Reino Unido), especificando que aun cuando Gibraltar no debía tener ya el estatuto de país tercero, su situación sigue siendo análoga a la de un país tercero en lo relativo a los intercambios de mercancías tanto con los Estados miembros como con los países terceros.

Siguiendo el hilo argumental, en materia de imposición indirecta ha de seguirse una interpretación vinculada a las exclusiones de Reino Unido sobre el territorio efectuadas en materia de libre circulación de mercancías, dada la complementariedad entre la circulación de mercancías y su imposición ${ }^{49}$.

El Tratado de Funcionamiento establece entre sus artículos 110 y 113 el marco general sobre las disposiciones fiscales. En concreto, dentro de las medidas de fiscalidad indirecta y de forma paralela a la unión aduanera las instituciones comunitarias han armonizado los impuestos de los Estados miembros, a través de diversas disposiciones. La armonización abarcó los impuestos sobre el valor añadido ${ }^{50} \mathrm{y}$ varios impuestos especiales como los aplicados a las bebidas alcohólicas, productos del tabaco y a los energéticos ${ }^{51}$.

47 Antón Guardiola, Gibraltar: un desafío..., op. cit., nº 91, p. 144.

48 Laws of Gibraltar. Disponible on line en http://www.gibraltarlaws.gov.gi/articles/1987s006.pdf y http://www.gibraltarlaws.gov.gi/articles/1993s017R.pdf [28 de mayo de 2017]

49 Martín Jiménez, A. y Hernández Guerrero, V., «El Derecho tributario de Gibraltar desde la óptica española y de la Unión Europea», visto en Del VALle GálVEZ, A. y GONZÁLEZ GARCía, I. Gibraltar, 300 años, Servicio de Publicaciones de la Universidad de Cádiz, Cádiz, 2004, pp. 237-311.

50 La primera norma tendente a configurar esta medida se introdujo con la Primera Directiva 67/227/CEE del Consejo, de 11 de abril de 1967, en materia de armonización de las legislaciones de los Estados miembros relativas a los impuestos sobre el volumen de negocios, modificada por las Directivas 69/463/CEE del Consejo, de 9 de diciembre de 1969 y la Directiva 77/388/ CEE del Consejo, de 17 de mayo de 1977; quedando en la actualidad configurada por medio de la Directiva 2006/112/CE del Consejo, de 28 de noviembre de 2006, relativa al sistema común del impuesto sobre el valor añadido

51 Desde un punto de vista general los impuestos especiales encuentran su marco general en la Directiva 2008/118/CE del Consejo, de 16 de diciembre de 2008, relativa al régimen general de los impuestos especiales, y por la que se deroga la Directiva 92/12/CEE. Respecto a cada uno de los temas en particular, la armonización de los productos del tabaco viene dada por la Directiva 95/59/CE del Consejo, de 27 de noviembre de 1995, relativa a los impuestos distintos de los impuestos sobre el volumen de negocios que gravan el consumo de labores del tabaco y sus actos 
Si en el caso de Gibraltar no se aplican las disposiciones comunitarias en materia de libre circulación de mercancías, tal y como señala la doctrina cualificada tampoco se aplicará la normativa fiscal indirecta tendente a eliminar las barreras fiscales intracomunitarias al ser un instrumento absolutamente necesario para conseguir la libre circulación ${ }^{52}$. Y si bien el artículo 110.2 del Tratado de Funcionamiento estipula el principio de no discriminación en la fiscalidad europea, el mencionado artículo del acta de adhesión excluye ipso iure de la aplicación a Gibraltar de la armonización de la legislación en relación a los impuestos sobre el volumen de negocios.

De esta forma la normativa europea, plasmada por el marco general que ofrecen los Tratados y el derecho derivado en materia de armonización fiscal no se aplicarán en ningún modo al territorio de Gibraltar dentro del actual modelo económico que sobre el territorio se configura, ni del IVA ni de los impuestos especiales del alcohol, tabaco ni productos energéticos.

A pesar de este claro límite, el Tribunal de Justicia de las Comunidades introduce un principio general en la citada sentencia de 23 de septiembre de 2003, que es el criterio según el cual las excepciones el Derecho comunitario han de interpretarse de forma estricta; por lo que como norma general, para que un territorio quede sustraído a la aplicación del Derecho comunitario es necesaria una exclusión expresa recogida bien en el Tratado, o en una norma de Derecho derivado (p. 26). Es el caso de la Directiva 77/799/CEE del Consejo, de 19 de diciembre de $1977^{53}$, relativa a la asistencia mutua entre las autoridades competentes de los Estados miembros en el ámbito de los impuestos directos y los impuestos sobre las primas de seguros. Mediante esta normativa las autoridades de los Estados miembros están obligadas al intercambio de todas las informaciones necesarias para la liquidación correcta de los impuestos sobre la renta y sobre el patrimonio, y de los impuestos indirectos.

El Gobierno de Gibraltar no desarrolló la referida normativa para aplicarla a su sistema de imposición indirecta, lo que motivó la apertura de un procedimiento de infracción contra Reino Unido por la Comisión Europea, el conse-

modificativos; la armonización de los productos energéticos por la Directiva 2003/96/CE del Consejo, de 27 de octubre de 2003, por la que se reestructura el régimen comunitario de imposición de los productos energéticos y de la electricidad y sus actos modificativos; y el alcohol por la Directiva 92/83/CEE del Consejo, de 19 de octubre de 1992, relativa a la armonización de las estructuras de los impuestos especiales sobre el alcohol y las bebidas alcohólicas y sus actos modificativos.

52 Antón Guardiola, Gibraltar: un desafío..., op. cit., p. 159.

53 Publicada en el DOUE, n L 336, de 27 de diciembre de 1977. 
cuente dictamen motivado con fecha de 15 de julio de 2002 y la interposición de un recurso de incumplimiento contra Reino Unido el 8 agosto del mismo año; proceso en el que se personó como coadyuvante el Reino de España.

El recurso se resolvió en la Sentencia del TJCE de 21 de julio de 2005 (asunto C-349/03, caso Comisión y España contra Reino Unido), en la que el Tribunal declaró que Reino Unido incumplió su obligaciones de aplicar en el territorio de Gibraltar la Directiva 77/799/CEE. A juicio del tribunal, la exclusión del artículo 28 no implica que Gibraltar quede fuera del deber de asistencia mutua de las autoridades competentes de los Estados miembros que impone la Directiva 77/799 (FJ. 53).

Por todo ello, a la luz de las normas de Derecho primario, de Derecho derivado, del artículo 28 del Acta de Adhesión de Reino Unido y de la jurisprudencia del Tribunal de Justicia de la Unión Europea, se desprende la idea de que sobre el territorio de Gibraltar no se aplica el ordenamiento comunitario regulador de la imposición indirecta, en la medida que se engloba dentro de la libre circulación de mercancías. Fuera de este concepto, en aplicación del principio de interpretación estricta sí generan aplicación las disposiciones fiscales que no sean tendentes a generar una armonización, lo que puede comprender la cooperación entre autoridades e intercambio de información tributaria.

Cuestión distinta al encuadre en el sistema fiscal comunitario de la armonización de la imposición indirecta constituye la configuración del sistema impositivo directo gibraltareño. En la actualidad las competencias en materia de fiscalidad directa no se encuentran directamente reguladas por la Unión Europea, por lo que la armonización es mucho menos intensa, limitándose a la aprobación de meras normas de coordinación fiscal entre los Estados miembros ${ }^{54}$. La única referencia que se encuentra expresamente reflejada en el TFUE es la del artículo 115, que permite la autorización, de aproximar las disposiciones legales, reglamentarias y administrativas de los Estados miembros que incidan directamente en el establecimiento o funcionamiento del mercado interior.

54 Tales como el Código de conducta sobre fiscalidad de las empresas, incluido en el anexo 1 de las conclusiones del Consejo ECOFIN, de 1 de diciembre de 1997, relativo a la política fiscal; la Directiva 2009/133/CE del Consejo, de 19 de octubre de 2009, relativa al régimen fiscal común aplicable a las fusiones, escisiones, escisiones parciales, aportaciones de activos y canjes de acciones realizados entre sociedades de diferentes Estados miembros y al traslado del domicilio social de una SE o una SCE de un Estado miembro a otro; o la Directiva 90/435/CEE del Consejo, de 23 de julio de 1990, relativa al régimen fiscal común aplicable a las sociedades matrices y filiales de Estados Miembros diferentes. 
Esta regulación concede la libertad para que los distintos Estados miembros puedan configurar con autonomía sus propios sistemas de imposición directa tanto de personas físicas como jurídicas, dando lugar a claras diferencias entre los distintos tipos de gravamen ${ }^{55}$. A pesar de la libertad de establecimiento en materia impositiva directa, constituye a efectos de la doctrina un interés de la Unión Europea la minoración de los regímenes fiscales que pudieran constituir una competencia desleal, para así evitar las injerencias en el normal funcionamiento del mercado interior o el surgimiento de paraísos fiscales ${ }^{56}$.

En este sentido se han establecido distintas normas, recomendaciones e informes que es preciso traer a colación. En primer lugar el Código de conducta sobre fiscalidad de las empresas, incluido en el anexo 1 de las conclusiones del Consejo ECOFIN, del 1 de diciembre de 1997, que constituye el inicio de las vías políticas intracomunitarias para asumir compromisos de lucha frente a los paraísos fiscales. Esta voluntad normativa ha evolucionado hasta los actos más recientes: la Recomendación de la Comisión, de 6 de diciembre de 2012, relativa a las medidas encaminadas a fomentar la aplicación, por parte de terceros países, de normas mínimas de buena gobernanza en el ámbito fiscal ${ }^{57}$.

En el punto tercero de la Recomendación se establecen unas normas mínimas de buena gobernanza en el ámbito fiscal, mediante las cuales un tercer país solo cumple las normas mínimas de buena gobernanza en el ámbito fiscal cuando ha adoptado medidas legislativas, reglamentarias y administrativas destinadas a cumplir las normas en materia de transparencia e intercambio de información; o cuando no aplica medidas fiscales perniciosas en la fiscalidad de las empresas. El concepto que ofrece el texto sobre medidas fiscales potencialmente perniciosas se refiere a aquellas que implican un nivel impositivo efectivo notablemente inferior, incluido el tipo cero, al aplicado habitualmente en ese tercer país ${ }^{58}$.

55 Y como establece la sentencia de la Gran Sala de de 15 de noviembre de 2011 (p. 97), también la libertad de determinación de las bases imponibles y el reparto de la carga fiscal entre los diferentes factores de producción y los diferentes sectores económicos.

56 ANTÓN GUardiola, Gibraltar: un desafío..., op. cit., p. 170.

57 Publicado en el DOUE n ${ }^{\circ} 338$, de 12 de diciembre de 2012, pp. 37 a 40.

58 El mismo punto tercero de la Recomendación establece criterios de evaluación, tales como si las ventajas se otorgan solo a no residentes o solo con respecto a las operaciones realizadas con no residentes; si las ventajas están totalmente aisladas del mercado nacional, no afectando a la base imponible nacional; si las ventajas se otorgan incluso si no exista ninguna actividad económica real ni presencia económica sustancial dentro del tercer país que ofrece las ventajas fiscales; si las normas para determinar los beneficios derivados de las actividades internas de los grupos de empresas multinacionales no se ajustan a los principios internacionalmente reconocidos, como las normas acordadas por la OCDE; o si las medidas fiscales carecen de transparencia. 
El sistema fiscal societario gibraltareño encuentra su principal regulación en la Companies (taxation and concessions) act, de $1967^{59}$. Debido a la diferencia de trato entre la tradicional regulación de las sociedades no residentes y las residentes la doctrina ha calificado al centro financiero de Gibraltar como offshore, a consecuencia de esta diferencia de trato causada en la rebaja de tipos impositivos se atraen a inversores extranjeros ${ }^{60}$. Respecto a las sociedades beneficiarias de tipos reducidos tras la reforma de la Income Tax Act, de 2010, el tipo general del impuesto de sociedades gibraltareño ha quedado fijado finalmente en un $10 \%$ para la modalidad beneficiada ${ }^{61}$.

Este modelo impositivo ha sido puesto en tela de juicio a raíz de la Sentencia de la Gran Sala del Tribunal de Justicia de 15 de noviembre de 2011, a instancias de la Comisión Europea tras un largo devenir procedimental y judicial ${ }^{62}$. El 27 de abril de 2002 el Gobierno de Gibraltar había anunciado su intención de reformar su legislación fiscal empresarial y de establecer un régimen fiscal nuevo para todas las sociedades de Gibraltar. El sistema pretendido por el Gobierno se basó en un impuesto sobre el número de empleados, un impuesto por superficie ocupada y una tasa de registro ${ }^{63}$.

Sobre esta reforma, la Sentencia del Tribunal de Justicia de 15 de noviembre de 2011 determinó que, partiendo de la idea de que un trato fiscal ventajoso puede llegar a constituir una ayuda estatal (salvo medidas con carácter general) la propuesta legislativa de reglamentación fiscal de las sociedades extraterritoriales gibraltareñas de 2002 constituyó ventaja selectiva. Debido a la combinación de las bases imponibles de la reforma (y aunque éstas tenían

59 Laws of Gibraltar. Disponible on line en http://www.gibraltarlaws.gov.gi/articles/1983-13o.pdf [30 de mayo de 2017]

60 ANTÓN GUARDiola, Gibraltar: un desafío..., op. cit., p. 172.

61 Laws of Gibraltar. Disponible on line en http://www.gibraltarlaws.gov.gi/articles/2010-21o.pdf [30 de mayo de 2017]

62 Vid. DíaZ Abad, N. «La fiscalidad de Gibraltar a examen», Revista Española de Derecho Europeo, enero-marzo de 2012, pp 7-8.

63 El impuesto sobre el número de empleados se pretendía aplicar a todas las sociedades de Gibraltar sobre el número de empleados de 3.000 libras por empleado y año; el impuesto por superficie ocupada «BPOT» (Business Property Occupation Tax) se pretendió aplicar a todas las sociedades que ocupasen propiedades en Gibraltar con fines empresariales al tipo equivalente general al que estén sujetas con arreglo al impuesto de bienes inmuebles en Gibraltar; y la tasa de registro anual de 150 libras para las sociedades sin ánimo de lucro y de 300 libras para las sociedades con tal ánimo (FJ. 12 de la sentencia). Además el límite máximo del impuesto sobre el número de empleados y de superficie ocupada sería igual al $15 \%$ de los beneficios. Respecto al límite máximo las empresas solamente pagarían el impuesto sobre el número de empleados y el impuesto de superficie ocupada si logran beneficios y si el importe los mismos no sobrepasaba el $15 \%$ de dichos beneficios 
carácter general) el Tribunal determinó que las mismas se encontraban concebidas de tal manera que en relación a las sociedades extraterritoriales (que por su naturaleza no tienen empleados ni locales) no disponían de tal base imponible, produciéndose así una discriminación entre sociedades territoriales que se pudiesen encontrar en una situación similar.

Es importante señalar que, como indica la doctrina cualificada en interpretación de esta sentencia, aunque la reforma que propuso el Gobierno de Gibraltar no entró en vigor tal jurisprudencia ofrece importantes elementos de análisis sobre la fiscalidad directa de Gibraltar, que en el presente trabajo señalamos ${ }^{64}$, que ya desde la presencia de Reino Unido en la Unión Europea generaba aristas de conflicto.

De este modo cabe citar la doctrina de economistas españoles que denuncian que el presente modelo económico altera y deprime el entorno económico del Campo de Gibraltar y la Costa del Sol ${ }^{65}$, aspecto controvertido por la doctrina británica que defiende un efecto positivo en la economía española ${ }^{66}$.

\section{ESTIMACIONES SOBRE LA APLICACIÓN DE UN PLAN DE MEDIACIÓN DIRIGIDO POR LA UNIÓN EUROPEA}

\section{II.1. Análisis desde una perspectiva bistórica}

El desarrollo de las relaciones diplomáticas entre el Reino Unido y España han dado lugar a un complejo escenario de negociaciones que, sin duda

64 Díaz ABaD, «La fiscalidad...», op. cit., p. 13.

${ }^{65}$ Como afirma Juan Velarde Fuentes, «Gibraltar pasa así, de ser plaza fuerte en el aspecto bélico, a buscar refugio en su conversión en una plaza de fiscalidad reducida y de aflujo de capitales. La polémica de Gibraltar altera [...] la economía de la Costa del Sol y de la babía de Algeciras con todo el denominado Campo de Gibraltar. La dinámica ligada a la globalización actual no parece favorecer el statu quo, que como reacción contra las medidas de Castiella, habia surgido en el Peñón, con empleo incluso de tablas input-output para basar un modelo econométrico destinado a frenar a España». VELARDE Fuentes, J., «Gibraltar, nuevos tiempos económicos», Crónica de Economía y Sociedad, nº 117, 28/05/2014. Disponible on line en http://crones.es/recuadrista.php?id=57\&id_recuadrista=1 [3 de junio de 2017]. Este autor mantiene esta misma tesis de los efectos del modelo económico ya afirmada en su obra, ID., Gibraltar y su Campo: Una economía deprimida, Ariel, Barcelona, 1970.

66 Según John Fletcher, en su informe «El Impacto Económico de la Economía de Gibraltar sobre el Campo de Gibraltar», solicitado por la Cámara de Comercio de Gibraltar en Septiembre de 2009, la economía de Gibraltar ejerce un impacto económico y positivo en la región de campo de Gibraltar por la importación de mercancías o el empleo de trabajadores fronterizos (entre otros). Disponible on line en http://www.gibraltarchamberofcommerce.com/the-impact-ofthe-economy-of-gibraltar-on-the-campo-de-gibraltar/ [3 de junio de 2017]. 
alguna, nos llevan a considerar y valorar la búsqueda de nuevos medios de solución a la controversia existente. Desde el punto de vista histórico es necesario traer a colación la Declaración de Lisboa de 10 de abril de $1980^{67}$, que la doctrina califica de acuerdo político no normativo entre el Ministerio de Asuntos Exteriores Español y el Foreing Office de Reino Unido ${ }^{68}$, fruto de las peticiones surgidas en el seno de Naciones Unidas. El documento anuncia como propósito entre las partes «resolver el problema de Gibraltar en un espíritu de amistad y de acuerdo conforme las resoluciones pertinentes de Naciones Unidas». Para ello se decidió iniciar las negociaciones con el fin de solucionar todas las diferencias. Entre otros compromisos se lleva a cabo el restablecimiento de las comunicaciones, la cooperación basada en la reciprocidad e igualdad de derechos y la apertura de un entendimiento más estrecho para las partes directamente perjudicadas, amén de reconocer el carácter beneficioso de la cooperación. Como particularidades, el Gobierno español reafirmó su posición en el restablecimiento de la integridad territorial salvaguardando los intereses de los gibraltareños y el Gobierno británico asumió respetar los deseos democráticamente plasmados de la población de Gibraltar.

La intención de negociar se reafirma con la Declaración de Bruselas de 27 de noviembre de $1984^{69}$, que según los expertos, interpreta, ejecuta y pone en práctica la Declaración de Lisboa ${ }^{70}$. El texto propone el establecimiento de igualdad y reciprocidad de derechos de los españoles en Gibraltar y los gibraltareños en España. Además de una declaración favorable al libre tránsito de personas, vehículos y mercancías entre Gibraltar y España, se estableció un proceso negociador a fin de solucionar las diferencias sobre la colonia británica tanto en la promoción de la cooperación económica, cultural, en materia de turismo y medio ambiente; como en el tratamiento de cuestiones de soberanía. Destaca la importancia de la suscripción de un acuerdo de celebración de reuniones de grupos de trabajo supervisadas periódicamente en encuentros de los Ministros de asuntos exteriores de cada respectivo gobierno.

A pesar de las declaraciones encaminadas a la apertura de la negociación, el llamado «proceso de Bruselas» no llegó a buen puerto. Como señala

67 Versión de la publicación del Ministerio de Asuntos Exteriores y Cooperación, La cuestión de Gibraltar, publicado en Madrid, 2009, pp 104-105.

68 REMIRo BROTONS, «Regreso a Gibraltar...», op. cit., pp. 145-146.

69 Versión de la publicación del Ministerio de Asuntos Exteriores y Cooperación, La cuestión de Gibraltar, publicado en Madrid, 2009. pp 106-107.

70 Remiro BRotons, «Regreso a Gibraltar...», op. cit., pp. 152-153. 
la doctrina dos son los hechos que dieron lugar al fracaso de este proceso de negociación: por un lado la firma de Reino Unido con la República Popular China de un acuerdo sobre el nuevo estatuto de Hong-Kong el 19 de diciembre de 1984, mediante el cual la antigua metrópoli devolvía la soberanía de la colonia con condiciones (lo que constituyó un precedente a tener en cuenta); y la negativa de Reino Unido de ejecutar acuerdos adoptados en el foro de Bruselas como la Declaración Conjunta sobre el aeropuerto de Gibraltar de 2 de diciembre de 1987, a cuya inejecución el ejecutivo británico de Margaret Thatcher argumentó la oposición de las autoridades locales gibraltareñas ${ }^{71}$.

La reactivación de un proceso negociador y creación de un foro común de diálogo transfronterizo no vendría dado hasta el Comunicado de Madrid emitido el 27 de octubre de 200472. En el mismo, los ministerios de exteriores británico y español acordaron realizar consultas sobre el establecimiento de un nuevo foro de diálogo con agenda abierta en la que Gibraltar tuviese voz propia. Además se puso de manifiesto el carácter positivo de la cooperación local entre Gibraltar y su zona circundante, acogiéndose a la idea de crear un Comité Conjunto entre el Gobierno de Gibraltar y la Mancomunidad de Municipios del Campo de Gibraltar. Esta intención constitutiva se plasmaría por igual en el Comunicado Conjunto de Madrid $^{73}$ de 16 de diciembre de 2004 entre las mismas partes, en el que se acordó el establecimiento de un nuevo foro de diálogo a tres bandas (Gobierno español, británico y gibraltareño) sobre Gibraltar y separado del proceso de Bruselas. Las distintas modalidades de este nuevo foro fueron las siguientes: tendría una agenda abierta en la que cualquiera de los participantes podría plantear asuntos relacionados con Gibraltar, cada parte tendría voz y participación propia con independencia del estatus constitucional, cualquier decisión debería ser acordada por cada uno de los tres participantes, el foro sería convocado a nivel ministerial por las tres partes cada doce meses, en el mismo se podrían crear los Grupos de Trabajo que fuesen necesarios y dicho foro, además, tendría en cuenta las actuaciones de la Comisión Mixta de Cooperación de 18 de noviembre de 2004 entre la Mancomunidad de Municipios de la Comarca de Campo de Gibraltar y el Gobierno de Gibraltar. Entre los principios de este foro estaría la creación de una atmósfera constructiva y la cooperación en beneficio y para la prosperidad de Gibraltar.

\footnotetext{
71 Ibid., pp. 157.

72 Versión de la publicación del Ministerio de Asuntos Exteriores y Cooperación, La cuestión de Gibraltar, publicado en Madrid, op. cit., pp. 132-133.

73 Ibid., pp. 134-135.
} 
Los resultados del Foro Tripartito fueron en principio positivos. Destacan así los Acuerdos de Córdoba de $2006^{74}$, cuya facilidad de diálogo se acrecentó entre otras razones debido a que las partes negociaron sin perjuicio de sus posiciones de soberanía y jurisdicción, como especifica en el punto tercero de dichos acuerdos. Entre otros asuntos se llegó a consenso en diversos temas, en los que se incluye la cuestión de las pensiones de antiguos trabajadores españoles en Gibraltar, el mejor uso del aeropuerto de Gibraltar, la circulación de personas, vehículos y mercancías, telecomunicaciones, la apertura del Instituto Cervantes con sede en Gibraltar, la cooperación portuaria y el compromiso con el proceso negociador. Si bien cabe calificar a estos acuerdos como meramente instrumentos políticos sin efecto vinculante entre las partes (soft-law), revelaron una clara voluntad tendente a la negociación.

A pesar de las muy positivas expectativas del Foro Tripartito, a partir del año 2010 se produjeron dos acontecimientos que marcaron el nuevo estancamiento del proceso negociador. Por un lado la delimitación de las aguas y los incidentes entre Guardia Civil, la Armada española, la Royal Gibraltar Police y la Royal Navy, motivado por el solapamiento de los Lugares de Interés Comunitario (LIC) ${ }^{75}$, que desembocó en un recurso ante el Tribunal de Justicia de la UE (Auto del Tribunal de Justicia de 12 de julio de 2012, asunto C-407/11); por otro lado, los cambios de gobierno producidos en el año 2011 (Mariano Rajoy en España y Fabián Picardo en Gibraltar ${ }^{76}$.

\section{II.2. ¿Posible solución negociada?}

No cabe duda de la naturaleza eminentemente política de las soluciones que se han planteado por ambas partes del contencioso, y de la congelación temporal de las distintas soluciones planteadas hasta el momento. A pesar de ello, se hace necesario reflexionar en el presente trabajo las más recientes de-

74 Ibid., pp 147-163.

75 Ecosistemas protegidos por la Directiva 92/43/CEE del Consejo, de 21 de mayo de 1992, relativa a la conservación de los hábitats naturales y de la fauna y flora silvestres. DOCE n L 206 de 22/07/1992 p. 0007-0050.

76 Del Valle GalveZ, A. «Gibraltar: del foro tripartito a cuatripartito: entre la cooperación transfronteriza y la soberanía», Revista ARI, Real Instituto Elcano, 21/2012, fecha 23/03/2012. Disponible on line en http://www.realinstitutoelcano.org/wps/wcm/connect/ec30ec804a9e28eabc61bdf3b87a73b6/ARI21-2012_del_Valle_Gibraltar_foro_cuatripartito_cooperacioon_soberania.pd f?MOD=AJPERES \&CACHEID=ec30ec804a9e28eabc61bdf3b87a73b6 [13de junio de 2017] 
claraciones políticas tendentes a una solución negociada así como del resurgimiento de un foro de negociación ${ }^{77}$.

Analizada la trayectoria histórica de los distintos procesos de negociación intentados y fracasados ya desde la apertura del proceso de descolonización en Naciones Unidas, y que ha perdurado en el tiempo a través de las Declaraciones de Lisboa y Bruselas; cabría preguntarse si la negociación como vía de solución extrajudicial de controversias ha fracasado y se deben replantear nuevos modelos de solución del conflicto aplicable al contencioso y a las distintas facetas y dimensiones del mismo, puestos de relieve en este trabajo.

Los distintos cambios de gobiernos, políticas y pretensiones de las partes han sido los principales agentes causantes del fracaso de las negociaciones. Además de este factor, los autores señalan un crecimiento del nacionalismo gibraltareño y su «identidad colectiva»: el sentimiento nacional crece debido a la creación de una identidad con las ideales de «fortaleza impenetrable»o «cementerio de Trafralgar». Este hecho se une al uso de colores y símbolos propios, la celebración de festivales ingleses, la introducción de cabinas telefónicas británicas (rojas), autobuses de dos pisos, nombres ingleses de calles, etc. De esta forma no son pocos los autores que determinan que los gibraltareños reclaman una identidad étnico-cultural distinta a la española bajo los atributos de la nacionalidad (un gobierno, un parlamento, radio y televisión, bandera e himno, Constitución y un día nacional) ${ }^{78}$; siendo favorables a la autodeterminación ${ }^{79}$. Por el contrario otros autores niegan la aplicación de la doctrina de la autodeterminación de Gibraltar, así como la devolución del territorio que habitan a España al ubicarse en ella una población «importada». Este sector doctrinal parte de la idea de que población importada, es aquella transferida por la potencia colonial frente a la población autóctona del lugar, lo que supone un obstáculo al derecho a la libre determinación de los pue-

77 Así es necesario traer a colación las declaraciones de Daniel Feetham, líder de la oposición gibraltareña, en su Conferencia pronunciada en la Real Sociedad Económica de Amigos del País de Jaén, el reciente día 3 de junio de 2014, en la que afirmó el «valor del deseo de trabajar hacia la normalidad de las relaciones de Gibraltar con España». El líder socialdemócrata afirmó que las partes del contencioso tenían «líneas rojas» (en el caso de Gibraltar aseguró que la jurisdicción, la soberanía y las aguas) y que en su configuración permitía un espacio político en el que se podían debatir acuerdos, trayendo a colación la igualdad de derechos de voz, voto y veto entre las partes intervinientes en el foro.

78 Muller, K., «Being «european» in Gibraltar», European Integration fournal, vol. 26, $\mathrm{n}^{\circ} 1$, March. Carfax Publishing, Londres, 2004, pp. 42-43.

79 Lincoln, S., «The Legal Status of Gibraltar: Whose Rock is it Anyway?», Fordham International Law fournal, vol. 18, Issue 1, 1994, p. 331. 
blos. Especialmente, cuando la población autóctona ha sido desalojada por la potencia colonial o la población importada supera a la autóctona.; llegando a la determinación de que dicha población «importada» no tendría derecho a la oposición de devolución del territorio ocupado ni a esgrimir un legítimo derecho a la autodeterminación ${ }^{80}$.

Es interesante la apreciación doctrinal de cómo, frente al movimiento integrador que constituye la Unión Europea para eliminar fronteras, se configura en la zona de Gibraltar el fenómeno sociológico de «sociedad de frontera», caracterizado por el rechazo al otro para construir una pauta de identidad (aunque sea inexistente) y laxitud en tal identidad; desembocando todo ello en complejas relaciones de vecindad en las que influye de forma determinante el modelo económico, la dinámica poblacional y la ausencia de un marco específico para la gestión de los recursos humanos ${ }^{81}$.

Por todo ello la mediación se perfila como una alternativa cualificada que es muy necesaria tener en cuenta en razón a varios argumentos: (i) la mejora que supone la intervención de un tercero imparcial que pueda contribuir al acercamiento de posturas; (ii) el vencimiento de los estancamientos que puedan surgir en el procedimiento de solución y la sucesión de gobiernos; (iii) el hecho de que dentro del carácter multidimensional del conflicto y en concreto la faceta de la aplicación del Derecho comunitario, la vía judicial comunitaria no ha ofrecido una solución efectiva, en razón del número de procedimientos incoados al efecto ${ }^{82}$.

Teniendo en cuenta lo expuesto, no sería aconsejable someter la cuestión de la integración económica y fiscal del territorio de Gibraltar en la Unión Europea a los medios jurídicos (como el recurso al Tribunal Internacional de Justicia o arbitraje) por dos razones fundamentales: (i) por las competencias cedidas por los Estados integrantes a la Unión Europa (España y Reino Unido entre ellos) en materia de libre circulación de mercancías y armonización fiscal, que establecería la jurisdicción del Tribunal de Justicia de la Unión Eu-

80 BAEza Betancort, F., Una aproximación jurídica al contencioso de Gibraltar. La clausula rebus sic standibus y el derecho de libre determinación de los pueblos, Real Sociedad Económica de Amigos del País, Las Palmas de Gran Canaria, 2001, pp. 168-169.

81 ODA ÁNGEL, F., «Gibraltar y las relaciones de vecindad: una tímida cooperación transfronteriza», en Del Valle Gálvez, Gibraltar, 300 años, op. cit., pp. 397-412.

82 Un ejemplo de mediación internacional puede verse en VALLEJo PeÑa, C., «Mediación internacional: el ejemplo del proceso de Oslo en el conflicto palestino-israelí», en CABRERA MERCADO, R. y QUESADA LÓPEZ, P.M., La mediación como método para la resolución de conflictos, Dykinson, Madrid, 2017, pp. 517-536. 
ropea; y (ii) porque según la doctrina sería desaconsejable para España judicializar la controversia de Gibraltar ante los altos riesgos de la posición jurídica española, ya que se deduciría que en un eventual procedimiento Reino Unido podría solicitar el tratamiento conjunto de cuestiones de soberanía, pudiéndose alterar la posición jurídica de España reforzada con los procedimientos de descolonización ${ }^{83}$.

No cabe de este modo duda alguna de que una de las propuestas más viables para el estudio de una mediación cercana e imparcial para ambas partes podría residir en la intervención de la Unión Europea, estableciendo un procedimiento en el que se dialoguen materias más allá de las competencias cedidas por los estados a la Unión. Sin duda las relaciones bilaterales Reino Unido-España han estado impregnadas de una europeización de los asuntos, sobre todo en el debate de la integración del territorio. Es preciso destacar, como ejemplo de este hecho, el Canje de Notas entre España y el Reino Unido en relación a la firma y posterior ratificación del Tratado relativo a la Adhesión de España a las Comunidades Europeas, hecho en Madrid el 13 de junio de $1985^{84}$. El Gobierno Español se dirigió al británico para comunicar que la firma del Tratado relativo a la Adhesión de España a las Comunidades Europeas no implicaba ninguna modificación de su posición respecto a Gibraltar y no afectaba al proceso negociador de Bruselas. La nota fue respondida por la embajada británica, afirmando que la adhesión de España a las Comunidades Europeas no implicaría ninguna modificación de la posición de Reino Unido respecto a Gibraltar en la aplicación de normativa comunitaria y que tampoco afectaría al proceso negociador.

Las partes desistieron desde la adhesión de España al inicio de una negociación orientada a la integración del territorio, entre otras circunstancias por la todavía joven incorporación de ambos Estados a la Comunidad Europea, lo que reveló que en la década de los 80 no se iniciasen negociaciones al respecto. No obstante, una vez que el proceso de integración europea adquirió mayores dimensiones la intervención de la Unión Europea se ha acentuado en dos planos: (i) por un lado mediante la aplicación de la potestad sancionadora de la Comisión Europea en los distintos procedimientos sancionadores (comentados en el epígrafe dedicado al análisis de la aplicación asimétrica del

83 Del Valle Gálvez, «¿De verdad...», op. cit., p. 144.

84 Versión de la publicación del Ministerio de Asuntos Exteriores y Cooperación, La cuestión de Gibraltar, publicado en Madrid, op. cit., pp 108-110. 
derecho comunitario) en materia tributaria y de Unión Aduanera; y (ii) por la vía judicial del Tribunal de Justicia.

Más allá de la intervención de la Unión Europea como organización internacional en el marco de sus competencias o por la vía judicial; acentúo los intentos políticos de acercamiento, como los revelados en las Conclusiones del Consejo europeo de Barcelona de 15 de marzo de $2002^{85}$. En concreto el Consejo Europeo en su conclusión 56 recibió con satisfacción la decisión del Reino Unido y de España de relanzar el Proceso de Bruselas sobre Gibraltar; y subrayó el apoyo de la Unión Europea al compromiso de ambos Gobiernos de superar sus diferencias sobre Gibraltar y concluir un acuerdo global; invitando a la Comisión a que explorase las posibles maneras en que la Unión Europea podría apoyar cualquier acuerdo al que se llegue.

La intervención de la Unión Europea en el conflicto de Gibraltar se ha puesto de relieve recientemente en relación a la investigación de los controles realizados por las autoridades españolas en la frontera de Gibraltar. En la propuesta de archivo de la denuncia CHAP 2013/2466 (2013/C 357/04) ${ }^{86}$ se exponen las conclusiones de la visita técnica producida a la zona fronteriza el 25 de septiembre de 2013, invitando la Comisión tanto a las autoridades españolas como británicas a considerar acciones para la gestión del paso fronterizo $^{87}$. Destaca el punto octavo de la propuesta de archivo de la denuncia, donde la Comisión anima a todas las autoridades pertinentes a reforzar su diálogo constructivo para alcanzar este objetivo (cooperación en persecución del contrabando y delitos transfronterizos).

De este modo la Unión Europea se ha erigido como un agente de especial importancia y referencia entre las partes en los últimos años. Por ello sería aconsejable: (i) por un lado la creación de un nuevo foro de diálogo donde intervenga tanto el Gobierno español como el británico, además de las au-

85 Unión Europea. Disponible on line en http://www.consilium.europa.eu/ueDocs/cms_Data/ docs/pressData/es/ec/70829.pdf [13de junio de 2017]

86 Publicado en el DOUE C 357/5 de 6.12.2013.

87 A modo ejemplificativo, a las autoridades españolas recomendó medidas encaminadas a optimizar el espacio físico en el espacio fronterizo, mejora del sistema de análisis de riesgo para la mejor definición de los casos en los que conviene realizar un control en profundidad del equipaje y del vehículo, y mejora de intercambio de información de contrabando de tabaco entablando mayor diálogo con las autoridades gibraltareñas. A Reino Unido recomienda en cambio la garantía de controles no sistemáticos y basados en un análisis del riesgo sobre los viajeros y sus pertenencias a la salida de Gibraltar, la armonización de la legislación gibraltareña a la europea sobre el tabaco y a desarrollar el intercambio de información sobre el contrabando de tabaco. 
toridades gibraltareñas (que disponen de competencias de autogobierno en virtud de la Constitución de Gibraltar de 2006 ${ }^{88}$ ) y la Comunidad Autónoma de Andalucía ${ }^{89}$ (con competencias propias cedidas por el artículo 148 de la Constitución Española de 1978 y el Estatuto de Autonomía de Andalucía); y (ii) por otro lado la intervención de la Unión Europea en calidad mediadora en este foro de diálogo, acercando posturas contrapuestas y reduciendo los riesgos que pudieran amenazar un proceso de diálogo y mediación (tales como los cambios de gobierno o movimientos nacionalistas antes comentados).

\section{II.3. El papel de la Unión Europa en el conflicto de Gibraltar. Situación post-Brexit}

Sin intención de defender un pronunciamiento sobre el fondo del asunto, es preciso destacar que la normalización del territorio de Gibraltar en la Unión Europea debe constituir un punto ineludible que las partes del contencioso habrán de afrontar para reducir su dimensión global.

Tomando como referencia las consideraciones recientemente enunciadas en la propuesta de archivo de la denuncia CHAP 2013/2466 (2013/C 357/04), es preciso recalcar que la Comisión invitó a las autoridades de Gibraltar a considerar la posibilidad de revisar la legislación gibraltareña reguladora de tabaco de 1997 con el objetivo ajustarla a la legislación de la Unión Europea sobre las exenciones fiscales y aduaneras para los viajeros con destino a la Unión y a los límites cuantitativos correspondientes para la importación de productos del tabaco libre de impuestos especiales. La Comisión igualmente animó a las autoridades de Gibraltar a tomar medidas adecuadas para garantizar que las importaciones a Gibraltar de productos del tabaco fuesen acordes

88 Un autor gibraltareño acepta la existencia de varias esferas de negociación, desde la supranacional reflejada por la Unión Europea hasta la sub-estatal, determinando la primacía del nivel sub-estatal aplicado al supuesto de Gibraltar por el estatuto jurídico de la Constitución de Gibraltar de 2006 y la diversidad de los puntos de vista políticos y diferenciando el punto de vista gibraltareño del británico. Vid. AzOPARDI, K., Sovereignty and the Stateless Nation. Gibraltar in the Modern Legal Context, Hart Publishing, Portland (Oregon), 2009, pp. 338-339.

89 Como defiende Yerga Cobos, la cooperación con la Junta de Andalucía se justificaría además por la cooperación de trabajadores andaluces en el territorio de Gibraltar, y el hecho de compartir un espacio geográfico común. Vid. Yerga CobOS, A., «La Junta de Andalucía y la cooperación entre Gibraltar y el Campo de Gibraltar», en Del Valle Gálvez, Gibraltar, 300 años, op. cit., pp. 368-370. 
con la demanda legítima; así como garantizar que los fabricantes de tabaco que suministren sus productos a los clientes en Gibraltar procedan a los controles adecuados de la cadena de suministro. Las valoraciones de la Comisión dan lugar a la conclusión de que existe una relación entre la no integración del territorio de Gibraltar en la Unión Aduanera ni la armonización fiscal (en el caso concreto de los impuestos especiales del tabaco) y los problemas fronterizos fruto de los controles legítimos efectuados por las autoridades españolas.

Siguiendo con este orden expositivo, es muy importante destacar el espíritu de los Acuerdos de Córdoba de 2006, los cuales buscaron el desarrollo económico y social tanto de Gibraltar como de la zona del Campo de Gibraltar, dejando «aparcado» el debate sobre la soberanía del territorio (que no tiene una dimensión comunitaria tan directa en comparación con la unión aduanera o la armonización fiscal ${ }^{90}$. Sería conveniente, pues, valorar la posibilidad de entablar un procedimiento de mediación específico sobre la integración del territorio de Gibraltar en la Unión Europea, relegando a otras vías de resolución de controversias el tratamiento de las dimensiones del contencioso relacionadas con la soberanía terrestre y marítima sobre los territorios en disputa en el que las diferencias entre las partes pudieran ser más abruptas (como la vía judicial del Tribunal Internacional de Justicia u el arbitraje, por ejemplo).

Dentro de la dimensión de integración comunitaria, por el contrario, la mediación adquiere indudablemente más relevancia frente a los medios jurídicos, puesto que a diferencia de la cuestión de la soberanía (que nunca antes se ha sometido a controversia ante tribunales internacionales), la aplicación del Derecho comunitario en Gibraltar ha sido llevado a la vía judicial (a través del Tribunal de Justicia de las Comunidades Europeas) sustanciado por diversos recursos de incumplimiento. La vía judicial europea, como he puesto de relieve en el epígrafe sobre la aplicación asimétrica del derecho comunitario en el territorio de Gibraltar, ha sido una vía de solución muy habitual para

90 Destacan las opiniones de Del Valle Galvez, que en sus valoraciones sobre los Acuerdos de Córdoba determinó que España había articulado tres niveles el tratamiento del tema de Gibraltar. El nivel superior sería el Proceso de Bruselas para la negociación bilateral de las cuestiones de soberanía; el nivel intermedio sería el Foro Trilateral para la cooperación transfronteriza; y un último nivel de cooperación subestatal Gobierno de Gibraltar-Mancomunidad de Municipios. Visto en Del Valle Galvez, A., «Los acuerdos del Foro de Diálogo sobre Gibraltar: la apuesta por la normalización», Revista ARI 107/2006, Real Instituto Elcano, fecha 19/10/2006. Disponible on line en http://www.realinstitutoelcano.org/wps/portal/rielcano/contenido?WCM_GLOBAL_ CONTEXT=/elcano/elcano_es/zonas_es/ari+107-2006 [13de junio de 2017]. 
controversias concretas en materia de libre circulación de mercancías y armonización fiscal, pero no ha aportado soluciones definitivas ni generales al contencioso. Estas soluciones adquieren una dimensión más política, requiriendo la manifestación de las voluntades concretas de Reino Unido y España, y se encuadrada en el contexto de la Unión Europea en razón de las competencias que atribuyen los Estados a la Organización en los Tratados. A mi juicio es el momento de plantear un modelo que se oriente a proporcionar una solución definitiva y superadora, que en principio podría venir de la mano de la mediación.

De este modo se podría señalar, como ejemplo de una posible normalización del territorio de Gibraltar en la Unión Europea el estatuto jurídico comunitario de las Islas del Canal, que aun no formando parte de las Islas Británicas y permaneciendo en territorio continental europeo su régimen aduanero y fiscal no está excluido del Acta de Adhesión de Reino Unido a la Unión Europea (y eventualmente tendría más sentido su diferenciación, ya que son territorios insulares a diferencia de Gibraltar que está unido físicamente al continente, siendo quizás la única frontera y aduana existente en territorio de la Unión Europea a día de hoy).

Ahora bien, los acontecimientos acaecidos en junio del 2016, con motivo del referéndum en Reino Unido (Brexit) ha provocado un cambio radical de la situación. El borrador de la UE sobre las líneas directrices de la situación después de la salida del Reino Unido de 31 de marzo en 2019 es claro: en su punto 22, establece que no habrá ningún acuerdo entre la UE y Reino Unido que pueda ser aplicado al territorio de Gibraltar sin el acuerdo previo entre de España y Reino Unido. Esto «rompe» la neutralidad que tradicionalmente ha mantenido la Unión Europea en el contencioso, pudiendo afirmar la existencia de un «veto español» en el plano comunitario.

Como señala la doctrina especializada, una vez Reino Unido deje de ser Estado Miembro de la Unión (con excepción de lo que se pueda pactar en el futuro tratado de retirada, u otros en condición de tercer país en virtud del artículo 218 del TFUE), no tendrá ninguna forma de invocar las libertades del mercado interior vigentes en territorio británico (y por tanto en Gibraltar) por interpretación negativa del Acta de adhesión 1972, especialmente, la libre circulación de servicios y de trabajadores. Y es, como afirma la profesora Araceli Mangas «aquí se vuelve al punto de partida, es decir, el Tratado de Utrecht, pudiendo impedir el paso de personas, servicios y mercancías a discreción» De esta forma España recobrará, sin inspecciones de la Comisión Europea, la plena facultad de hacer controles tan rigurosos como crea oportunos y conve- 
nientes, y, llegado el caso, cerrar el paso cuando lo estime necesario o denegar la entrada de gibraltareños concretos conforme a las normas para las fronteras exteriores ${ }^{91}$.

\section{CONCLuSiOnes}

Dentro de los modelos clásicos de solución de controversias, la mediación internacional se perfila como un sistema basado en la intervención de un tercero para acercar posturas y proponer soluciones a la controversia. Si bien tradicionalmente se ha configurado en el Ordenamiento jurídico internacional tanto en el plano regional como en el universal; su promoción y propuestas de mejora llevados a cabo principalmente por el Secretario General de Naciones Unidas y la doctrina científica permiten encuadrar su actualización dentro de los nuevos modelos y escenarios de solución pacífica de controversias, así como su integración en modelos mixtos en conjunto con el arbitraje.

El procedimiento de mediación internacional deberá estar presidido por el principio de simplificación en su tramitación y desarrollo, diferenciador respecto de otros modelos de solución de controversias y elemento clave a la hora de la consecución de un acuerdo participado por las partes. Este principio deberá incluir por igual a la duración, no resultando positiva la inclusión de un plazo siempre que el procedimiento de mediación se sustente en una viabilidad objetiva.

Teniendo en cuenta lo expuesto, entendemos que el ejercicio de la labor del mediador internacional deberá estar influenciada por las Directrices de las Naciones Unidas para una Mediación Eficaz, que si bien no poseen el valor vinculante de los Tratados orientan la labor del mediador internacional a un planteamiento profesional, ofreciendo además una interpretación cualificada de la aplicación práctica de la mediación internacional. En concreto destaca la actuación bajo los principios de imparcialidad, coherencia y transparencia; así como de actuación bajo el consentimiento de las partes a lo largo de todo el procedimiento de mediación, incluyéndose la ejecución de los acuerdos resultantes. Destaca por igual la participación de más agentes capaces de intervenir positivamente en el procedimiento de mediación aunque no sean sujetos de

91 Mangas Martin, A., «La retirada del Reino Unido de la Unión Europea», Revista de Ciencias Furídicas y Sociales, vol. 19, n 1, 2016, pp 29-63. 
Derecho Internacional stricto sensu, como grupos religiosos, entidades locales, u órganos subnacionales con competencias atribuidas o propias.

$\mathrm{El}$ acuerdo que ponga fin a la mediación, si lo hubiere, debería tratar todos los puntos conflictivos en los que se pudiera suscribir un pacto e intentar atajar todas las cuestiones estableciendo mecanismos o instituciones como garantía objetiva y vía de ejecución de cara a futuras controversias, como el recurso a otros métodos pacíficos y organismos comunes como un Tribunal, Asamblea u organización internacional. En este sentido, a la hora de aplicar el procedimiento de mediación al contencioso de Gibraltar entre Reino Unido y España, sería necesario partir de la idea de la complejidad del mismo y de sus dimensiones en materia de soberanía terrestre, soberanía marítima e integración europea del modelo económico.

En referencia al conflicto de soberanía terrestre, el territorio cedido ostenta diversos títulos en función del cedido en el Tratado de Utrecht, la zona del Monte Calpe adquirida por prescripción adquisitiva y el istmo, territorio este último en controversia internacional respecto del cual Reino Unido alega la existencia de prescripción adquisitiva y España la niega, alegando la existencia de múltiples protestos desde que se erigió por primera vez la llamada «verja» en el año 1909. Por otra parte, en relación con el conflicto de soberanía marítima, la controversia está sujeta a dos interpretaciones distintas: para España no existen aguas británicas más allá del puerto de Gibraltar, en aplicación de la teoría de la «costa seca», mientras que Reino Unido defiende la existencia de sus aguas jurisdiccionales y soberanía marítima ${ }^{92}$.

El conflicto en su dimensión de integración europea, si bien en referencia al estatus de los ciudadanos de Gibraltar como ciudadanos de la Unión Europea parece ya superado jurisprudencialmente, alcanzaría una mayor disputa en relación a la aplicación asimétrica del Derecho de la UE al modelo económico y fiscal de Gibraltar. El artículo 28 del Acta de Adhesión de Reino Unido a las Comunidades Europeas excluye de la aplicación a Gibraltar, entre otros, de la Unión Aduanera y la armonización de la imposición indirecta; aspectos que han repercutido en diversos incumplimientos incoados por España en sede judicial europea y que acrecienta el contencioso respecto de los controles

92 En este sentido, Reino Unido ejerce un papel importante, a pesar de la oposición de España, en el control de las aguas adyacentes a la colonia británica de Gibraltar y en las aguas del Estrecho del mismo nombre, aunque no tanto en materia de navegación. Para más información vid. GutiérRez CAstillo, V.L., «Legal regime on navigation throuth the Strait of Gibraltar: the role of its coastal States», Il Diritto Maritimo, Génova, aprile-giugno, 2017, pp. 345-366. 
fronterizos que trae consigo. Además, el sistema de imposición directa sobre sociedades ha sido parcialmente puesto en tela de juicio por el Tribunal de Justicia de la Unión Europea en el sentido del tratamiento diferenciado y las ventajas selectivas otorgado por Gibraltar a las sociedades extraterritoriales.

Fracasado el modelo de negociación instado desde el proceso de descolonización iniciado por Naciones Unidas, consensuado en los acuerdos de Lisboa, Bruselas y el más reciente de 2004 que constituyó el Foro Trilateral (entre otras causas por cambios de gobierno y surgimiento de posiciones nacionalistas); se hace ahora necesario buscar nuevos modelos de solución de controversias para el contencioso teniendo muy en cuenta las distintas dimensiones del mismo y el tratamiento diferenciado que requieren. Dentro de los medios pacíficos aplicables a la integración europea la mediación se posiciona como una hipótesis cualificada frente a la vía judicial o el arbitraje en razón a las competencias cedidas por los Estados a la Unión Europea y la necesidad de obtener una solución general y definitiva en la que participen los dos estados en conflicto. El inicio de medios políticos podría implicar el estableciendo de un foro de diálogo entre el Reino Unido, España, Gibraltar y Andalucía (estas últimas como entidades subnacionales con competencias internas cedidas y por cercanía geográfica) con el patrocinio de una mediación a manos de la Unión Europea; para así conseguir crear un entorno de diálogo y acercamiento de posturas donde se trate, con una mayor viabilidad de éxito el estudio de un nuevo modelo económico y fiscal para Gibraltar en la Unión Europea. En tal escenario, Reino Unido tendría que volver a negociar un acuerdo de libre comercio con España para garantizar la supervivencia económica de Gibraltar, en aspectos tan elementales como permitir pasar a los trabajadores españoles. 